\title{
Potentiometric Flow Injection Analysis of Bromhexine Hydrochloride and its Pharmaceutical Preparation Using Conventional and Coated Wire lon-Selective Electrodes
}

\section{Nour T. Abdel-Ghani* 1, Yousry M. Issa 2 and Howayda M. Ahmed}

Chemistry Department, Faculty of Science, Cairo University, Giza, Egypt.

\begin{abstract}
Bromhexine hydrochloride ion-selective electrodes (conventional type) based on bromhexinium tetraphenyl borate (I) and bromhexinium-phosphotungstate (II) were prepared. The electrodes exhibited mean slopes of calibration graphs of 59.4 $\mathrm{mV}$ and $59.8 \mathrm{mV}$ per decade of bromhexine concentration at $25^{\circ} \mathrm{C}$ for electrode (I) and (II), respectively. Both electrodes could be used within the concentration range $3.16 \times 10^{-5}-1.00 \times 10^{-2} \mathrm{M}$ bromhexine within the $\mathrm{pH}$ range $2.0-4.5$. The standard electrodes potentials were determined at different temperatures and used to calculate the isothermal coefficients of the electrodes, which were 0.00065 and $0.00050 \mathrm{~V}^{\circ} \mathrm{C}^{-1}$ for $(\mathrm{I})$ and $(\mathrm{II})$, respectively. The electrodes showed a very good selectivity for bromhexine with respect to a number of inorganic cations, amino acids and sugars. The electrodes were applied to the potentiometric determination of bromhexine hydrochloride and its pharmaceutical preparation under batch and flow injection conditions. Graphite, copper and silver coated wires were prepared, characterized and successfully applied as sensors for the drug under investigation.
\end{abstract}

\section{Key words}

Ion-selective electrodes, bromhexine hydrochloride, conventional and coated wire electrodes, flow injection analysis and conductimetry. 


\section{Introduction}

Bromhexine hydrochloride; 2-Amino-3,5-dibromobenzyl (cyclohexyl) methylamine, mol. mass: 412.6, [CAS-611-75-6].<smiles>CN(Cc1cc(Br)cc(Br)c1N)C1CCCCC1</smiles>

Bromhexine hydrochloride is a mucolytic used in the treatment of respiratory disorders associated with productive cough. It has been determined by different techniques including spectrophotometry $[1,2,3], \operatorname{HPLC}[4,5,6]$, colorimetry $[7,8]$, TLC [9], Flow-injection-spectrophotometry [10], GC [11], Ion-Selective Electrode (ISE) [12], Hybrid Linear Analysis [13], capillary isotachophoresis [14], Absorption Spectrophotometry and Electrophoresis $[15,16]$.

In the present work, plastic membrane electrodes, selective for bromhexine hydrochloride are constructed, their performance characteristics studied and then used to determine the drug both in batch and with a flow injection technique, which is considered a very efficient way of improving the performance characteristics of ISEs. The electrodes are based on the incorporation of bromhexinium tetraphenylborate (Brom-TPB) and bromhexinium phosphotungstate (Brom-PT) ionexchangers in poly (vinyl chloride) (PVC) membranes plasticized with dibutylphthalate (DBP). The selectivity of the electrodes was also tested in batch and FIA techniques. Fine-graphite, copper and silver wires coated with a solution mixture of liquid ion-exchangers and poly (vinyl chloride) in THF were used as an ion-selective electrodes for bromhexinium cation.

\section{Experimental}

All chemicals used were of analytical grade, double distilled water was used throughout all experiments. Pure grade bromhexine hydrochloride and its 
pharmaceutical preparation (Bisolvon tablets, $8 \mathrm{mg} /$ tablet), were provided by Chemical Industries Development Co., (Egypt), sodium tetraphenylborate (NaTPB) and phosphotungstic acid (PTA) were obtained from Fluka. The ion-exchangers, bromhexinium tetraphenylborate (Brom-TPB) (white powder) and bromhexinium phosphotungstate (Brom-PT) (buff powder) were prepared as previously described [17]. The chemical composition of the ion-exchangers as identified by elemental analysis was found to be 1:1 and 3:1 for (Brom-TPB) and (Brom-PT), respectively.

Potentiometric measurements as well as the construction of an FIA system and the methods used for recording the peaks as a function of the potential were performed as mentioned in our previously studies $[17,18]$.

The conductivities were measured with the aid of an Engineered Systems \& Designs [ESD] conductometer model 72 (Conductance/TDS) (USA) provided with conductivity cell of 1.000 cell constant.

Several membrane composition electrodes as well as graphite, copper, and silver wires ( $3 \mathrm{~mm}$ in diameter and $12 \mathrm{~cm}$ in length) were constructed and used as previously described [19].

Conductimetric measurements and determination of the solubility product of the Brom-TPB and Brom-PT ion-exchangers were carried out as in previously described method [20]. The solubility (s) and the solubility product (Ksp) of the precipitates, Brom-TPB and Brom-PT were calculated using the following equations:

$$
\begin{array}{lll}
s=K s \times 1000 /\left(\lambda_{\circ} \text { Brom-TPB }\right) & \text { and } & K s p=s^{2} \\
s=K s \times 1000 /\left(\lambda_{\circ} \text { Brom-PT }\right) & \text { and } & K s p=27 s^{4}
\end{array}
$$

where $\mathrm{Ks}$ is the specific conductivity of a saturated solution of the ion-associate, determined at $25^{\circ} \mathrm{C}$ and corrected for the effect of the solvent and $\lambda_{0}$ is the equivalent conductance at infinite dilution and it is obtained from the ionic conductance of the constituents ions using Kohlrausch's law of independent migration. 


\section{Results and discussion}

\section{Optimization of the ISE in batch conditions}

\section{Composition of the membrane}

Several membrane compositions were investigated, the best performance was obtained by using composition containing 10\% Brom-TPB or Brom-PT, $45.0 \%$ of each PVC and DBP with resulting slopes of 59.4 and $59.8 \mathrm{mV} /$ decade of concentration for (I) and (II) electrodes, respectively after minimum presoak of $1 / 2 \mathrm{~h}$ at $25^{\circ} \mathrm{C}$. The usable concentration range was $3.16 \times 10^{-5}-1.00 \times 10^{-2} \mathrm{M}$ for both electrodes and response time $\leq 10 \mathrm{~s}$. The above optimum composition was used to prepare membrane electrodes for all further subsequent investigations.

\section{Effect of soaking}

Freshly prepared electrodes can be used after presoaking in $10^{-3} \mathrm{M}$ bromhexine hydrochloride where the mean slopes are 59.4 and $59.8 \mathrm{mV} / \mathrm{decade}$ of concentration at $25^{\circ} \mathrm{C}$ for electrodes (I) and (II), respectively. In the present work, the slopes remained stable over 10 and 17 days and then, they sharply decreased reaching 44.5 and $46.2 \mathrm{mV} /$ decade of concentration for electrodes (I) and (II), respectively. The electrodes responded correctly within the concentration range $3.16 \times 10^{-5}-1.00 \times 10^{-2} \mathrm{M}$ and their response has not been affected by soaking. On the other hand, the electrode that has been kept dry in a closed vessel and stored in a refrigerator showed nearly constant slope value and the same response properties extending to about 45 and 30 days for electrodes (I) and (II), respectively.

For the coated wire electrodes, it was found that the plastic membrane coat must be reformed prior to every use by immersing the bared terminal of the electrode in the solution mixture containing the ion-exchanger for a few seconds and left it to dry in air. For Brom-TPB coated wires electrodes, the calibration graph slopes for the fresh graphite, copper and silver were 61.9, 58.7 and 60.0 $\mathrm{mV} /$ decade, respectively. After daily use of the graphite, copper and silver electrodes for 14,7 and 11 days the slopes decreased to $48.6,42.4$ and 44.8 $\mathrm{mV} /$ decade, respectively. While for Brom-PT coated wires, the calibration graph 
slopes were $63.3,62.0$ and $60.7 \mathrm{mV} /$ decade for the graphite, copper and silver coated electrodes, respectively, and after daily use of the graphite, copper and silver electrodes for 16,8 and 16 days the slopes decreased to $47.5,45.6$ and 46.5 $\mathrm{mV} /$ decade, respectively. The usable concentration range of the electrodes was $1.77 \times 10^{-5}-1.00 \times 10^{-2} \mathrm{M}$. Also the wire electrodes do not need conditioning before each use. Fig. 1 shows representative calibration graphs for Brom-PT graphite coated electrode.

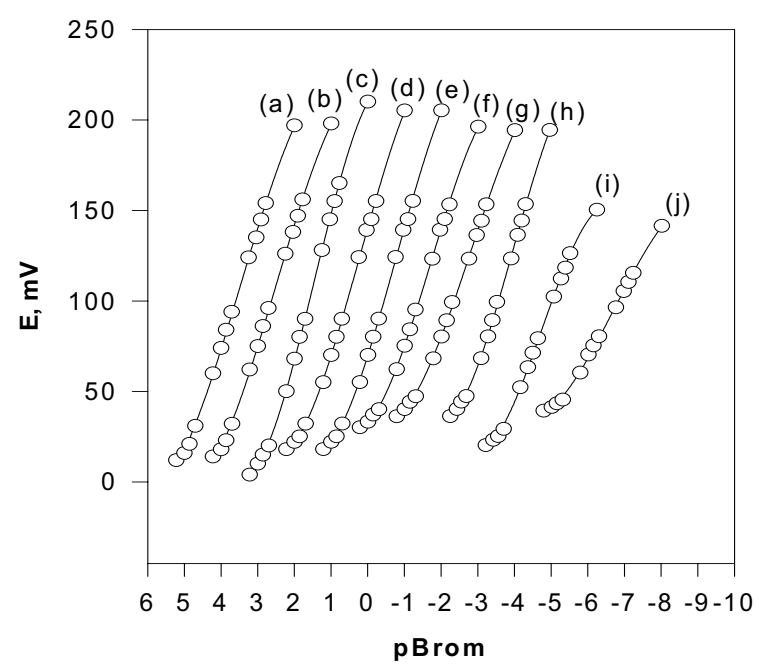

Fig. 1. Calibration graphs at $25^{\circ} \mathrm{C}$ for Brom-PT graphite coated electrode for $1 \mathrm{~h}$ (a), 6h (b) and 24h (c), 3 (d), 6 (e), 9 (f), 12 (g), 14 (h), 15 (i) and 16 days (j).

Note: All graphs start at $\mathrm{pBrom}=6$.

pBrom $=-\log$ [concentration of bromhexine $\mathrm{HCl}$ ].

\section{Effect of temperature of the test solution}

To study the thermal stability of the electrodes, calibration graphs (cell potential, $E_{\text {cell }} \cup \mathrm{s}$ pBrom) were constructed at different test solution temperatures covering the range $25-65^{\circ} \mathrm{C}$. The isothermal coefficients $(\mathrm{dE} / \mathrm{dt})$ of the electrodes were calculated with the help of these graphs [21] and found to be 0.00065 and 
$0.00050 \mathrm{~V} /{ }^{\circ} \mathrm{C}$ for Brom-TPB and Brom-PT electrodes, respectively. These values indicate a fairly good thermal stability of the electrodes within the investigated temperature range and show no deviation from the theoretical Nernstian behavior.

\section{Optimization of FIA response}

The flow injection measurements were carried out in a two-line configuration as shown in Fig.2. The dispersion coefficient ranged between 1.45 and 1.49, i.e., limited dispersion coefficients that aid optimum sensitivity and fast response of the electrodes [22].

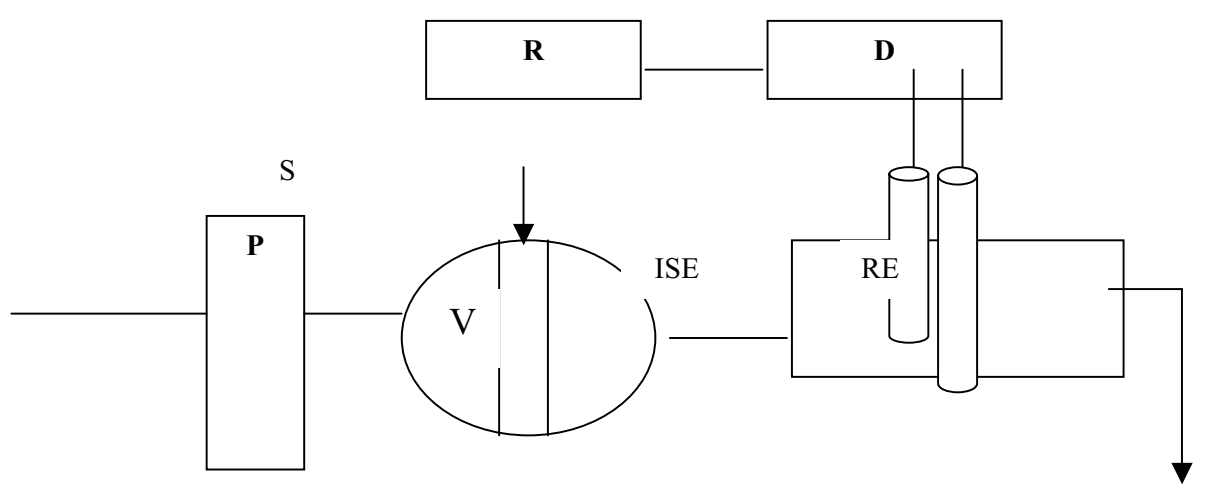

W

Figure 2. Single-stream FIA manifold for bromhexine hydrochloride determination; S, sample; $P$. peristaltic pump; V, injection valve; ISE, Brom-electrode; RE, reference electrode; $D$, detector. R, recorder; W, waste.

\section{Optimization of operational conditions}

\section{Optimization of flow rate and sample volume.}

Several flow rates $\left(4.15-27.00 \mathrm{ml} \mathrm{min}^{-1}\right)$ were checked. A flow rate of $9.7 \mathrm{ml}$ $\mathrm{min}^{-1}$ was adopted, providing about $99 \%$ of the maximum peak height obtained by higher flow rates, with a shorter time to reach the baseline and less consumption of 
the carrier. The sample volume was optimized at flow rate $9.7 \mathrm{ml} \mathrm{min}^{-1}$ by injecting volumes between (5-340 $\mu \mathrm{l})$ of $10^{-3} \mathrm{M}$ bromhexine. A sample loop of size $75 \mu \mathrm{l}$ was chosen as a compromise between reagent consumption and signal size and used through out this work. Fig. 3 shows typical recordings obtained from Brom-TPB under optimum conditions.

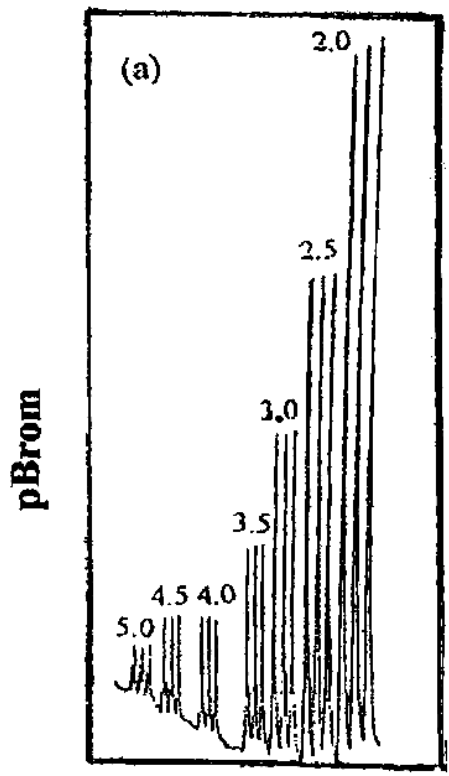

Time

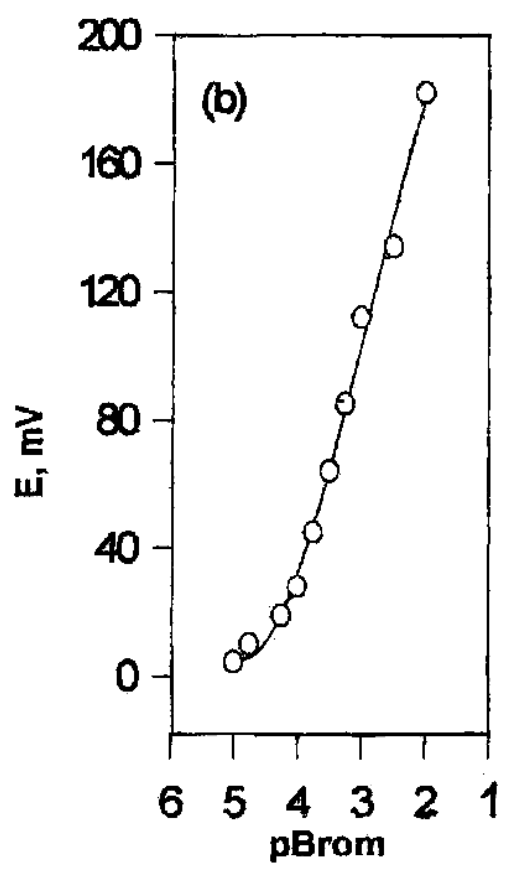

Fig.3. The FIA recordings (a) and their corresponding callbration graphs (b) obtained for Brom-TPB electrode at ontimum FIA conditions

\section{Optimization of $\mathrm{pH}$}

The effect of the $\mathrm{pH}$ of the test solution on the electrode potential was studied in batch and FIA measurements as previously described [17]. It was found that the (I) and (II) electrodes do not respond to $\mathrm{pH}$ changes in the range 2.0-4.5 in both batch and FIA conditions. At a pH less than 2.0, the drop in potential of both electrodes (I) and (II) may be due to penetration of chloride ions into the membrane network at the interface between the test solution and the matrix of membrane. 
While the gradual decrease in potential observed at a $\mathrm{pH}$-value more than 4.5 for both electrodes may be due to the deprotonation of bromhexine hydrochloride in the solution, which leads to a consequent decrease in its concentration [17]. These results were confirmed by $\mathrm{pH}$-metric determination of the protonation constant of bromhexine, the mean pKa value obtained was 4.5 , indicating that the decrease in $\mathrm{pH}$ outside the above the working range is due to the formation of the free base.

\section{Electrode response in FIA}

The slope of the calibration plots in FIA was high compared with batch measurements, where potential is measured under conditions very close to the equilibrium at the membrane-solution interface [23]. The slopes of the calibration graphs were 72.9 and 68.6 in FIA compared to the batch 59.4 and $59.8 \mathrm{mV}$ per concentration decade for Brom-TPB and Brom-PT electrodes, respectively. The usable concentration ranges of the electrodes in FIA are $5.62 \times 10^{-5}-1.00 \times 10^{-2}$ which is nearly the same as in batch mode.

\section{Selectivity}

The selectivity of the ion-pair associates based membrane electrode depends on the selectivity of the ion-exchange process at the membrane-test solution interface and the mobilities of the respective ions within the membrane [24]. The influence of some excipients, inorganic cations, amino acids and sugars on the response of bromhexinium electrodes was investigated in FIA and batch conditions applying separate solution method as previously described [25].

The selectivity coefficient $\mathrm{K}_{B r o m, J^{Z+}}^{\text {Pot }}$ of the electrodes towards some inorganic cations: $\mathrm{NH}_{4}{ }^{+}, \mathrm{Na}^{+}, \mathrm{Mg}^{2+}, \mathrm{Cu}^{2+}, \mathrm{Ca}^{2+}, \mathrm{Zn}^{2+}, \mathrm{Ni}^{2+}, \mathrm{Mn}^{2+}, \mathrm{Pb}^{2+}$ and $\mathrm{Al}^{3+}$ were $9.8 \times 10^{-4}$ $-2.6 \times 10^{-5}$ and $1.9 \times 10^{-3}-4.3 \times 10^{-4}$ under batch and FIA conditions, respectively, for both electrodes, which reflect very high selectivities of the investigated electrodes for the bromhexinium cation. The selectivity mechanism is mainly based on the sterospecificity and electrostatic environment, and is dependent on how much fitting is present between the locations of the lipophilicity sites in the two competing species on the bathing solution side and those present in the receptor of 
the ion-exchanger [25]. In other words, the distribution of the active components situated at the electrode surface allow the primary ions to react but do not enter the membrane phase under zero-current conditions and this explained the fact that the electrode surface is not completely flat but has depressions and hills [26]. The inorganic cations do not interfere because of differences in the ionic size, the mobility and the permeability. Also, the smaller is the energy of hydration of the cation, the greater is the response of the membrane. The electrodes exhibit good tolerance towards amino acids and sugars, where it was found that the Brom-TPB electrode could be safely used without interferences in the presence of glucose, fructose, maltose, lactose, ascorbic acid, vitamine $\mathrm{B}_{1}$, leucine, alanine and glycine up to $320,482,233,165,210,133,96,202$ and 1166 folds of the investigated drug and $400,385,200,145,167,154,112,198$ and 960 folds in the case of the BromPT electrode.

\section{Conductometric determination of the solubility product of Brom-TPB and Brom-PT ion-exchangers}

The solubility products of the precipitated ion-exchangers were determined as previously described [27] and found to be $6.2 \times 10^{-6}$ and $1.2 \times 10^{-17}$ for Brom-TPB and Brom-PT, respectively. These values indicate that the solubilities of the ionexchangers are very low $\left(2.5 \times 10^{-3}\right.$ and $\left.2.6 \times 10^{-5} \mathrm{~mol} / \mathrm{l}\right)$. Consequently, the equilibrium constants of the reactions,

$$
\begin{gathered}
\text { Brom + Na-TPB }=\text { Brom-TPB }+\mathrm{NaCl} \\
3 \mathrm{Brom}+\mathrm{H}_{3} \mathrm{PTA}=\text { Brom }_{3}-\mathrm{PT}+3 \mathrm{HCl}
\end{gathered}
$$

are $1.6 \times 10^{5}$ and $8.5 \times 10^{16}$, respectively, which reflects that the reaction is more than $99.9 \%$ complete. In the above equilibria, the solubilities of the undissociated ionexchangers in water (i.e. the intrinsic solubility) were omitted as they only have a negligible contribution to the total solubility. 


\section{Analytical applications}

Bromhexine hydrochloride is determined potentiometrically using the investigated electrodes under batch conditions with conventional and coated wire electrodes by standard additions methods [28]. Fore sampling of tablets (Bisolvon, $8 \mathrm{mg}$ per tablet), 40 tablets were ground together and appropriate weights of each were dissolved in the equivalent volume of $0.01 \mathrm{M} \mathrm{HCl}$ and diluted to $50 \mathrm{ml}$ with bidistilled water.

In batch technique using conventional electrode, the mean recoveries of the amounts taken (10-100 $\mathrm{mg}$ ) ranged from 97.6 to $99.8 \%$ with $\mathrm{RSD}=0.20-1.20 \%$ for Brom-TPB and from 97.6 to $99.9 \%$ with RSDs $=0.04-0.50 \%$ for Brom-PT electrodes. While for coated wire electrodes, the mean recoveries of the amounts taken $(10-100 \mathrm{mg}$ ) ranged from 98.0 to $101.9 \%$ with $\mathrm{RSD}=0.4-1.9 \%$ and 97.8 to $100.6 \%$ with RSD $=0.4-1.6 \%$ for graphite-pencil rod of Brom-TPB and Brom-PT electrodes, respectively and ranged from 97.7 to $99.9 \%$ with RSD $=0.1-1.0 \%$ and 97.8 to $99.1 \%$ with RSD $=0.1-1.3$ for Brom-TPB and Brom-PT electrodes using copper coated wire, respectively, and ranged from 97.5 to $100.2 \%$ with RSD $=0.2$ $1.2 \%$ and 98.8 to $101.6 \%$ with RSD $=0.2-1.5 \%$ for Brom-TPB and Brom-PT electrodes, respectively using silver coated wire.

The results of the determination of bromhexine hydrochloride in its pure state or pharmaceutical preparation by conductimetric method for the amounts taken (10$100 \mathrm{mg}$ ) showed good recovery ranging from 98.2 to $99.8 \%$ with RSD $=0.1-1.0 \%$ and 99.1 to $100.7 \%$ with RSD $=0.1-1.4 \%$ in case of using Na-TPB and PTA as titrants, respectively.

Under FIA conditions, The mean recoveries for the amounts taken (10-100 $\mathrm{mg}$ ) ranged from 97.7 to $99.1 \%$ with RSDs of 0.1-1.8 for Brom-TPB electrode and from 96.4 to $98.8 \%$ with RSDs $=0.1-1.4$ for Brom-PT electrode. These methods are compared with each other by applying F- and t- tests [29] and with the official method (potentiometric titration of bromhexine hydrochloride with standard $\mathrm{NaOH}$ ) [30]. The values given in Table 1, show that the present methods are of comparable 
precision to each other and there is no significant difference between the mean values obtained by the three methods.

\begin{tabular}{|c|c|c|c|c|c|c|}
\hline \multirow[b]{2}{*}{ Method } & \multicolumn{3}{|c|}{ Pure solutions } & \multicolumn{3}{|c|}{ Bisolvon tablets ( $8 \mathrm{mg} /$ tablet) } \\
\hline & $\mathrm{X} \pm \mathrm{S} . \mathrm{E}$ & $\begin{array}{c}\mathrm{RE}^{*} \\
\%\end{array}$ & $\begin{array}{c}\mathrm{F}^{3,3} \text { value } \\
(9.27)^{* *}\end{array}$ & $\mathrm{X} \pm \mathrm{S} . \mathrm{E}$ & $\begin{array}{c}\mathrm{RE}^{*} \\
\%\end{array}$ & $\begin{array}{c}\mathrm{F}^{3,3} \text { value } \\
(9.27)^{* *}\end{array}$ \\
\hline Official method & $100.0 \pm 0.06$ & 0.01 & & $99.5 \pm 0.05$ & 0.5 & \\
\hline \multicolumn{7}{|c|}{ Brom-TPB electrode (I) } \\
\hline \multicolumn{7}{|l|}{ Method (A) } \\
\hline -Conventional & $99.2 \pm 0.14$ & 0.81 & 5.9 & $98.3 \pm 0.28$ & 1.73 & 7.8 \\
\hline -Graphite coated & $100.0 \pm 0.50$ & 0.05 & 2.5 & $98.7 \pm 0.36$ & 1.28 & 5.4 \\
\hline -Copper coated & $99.2 \pm 0.11$ & 0.83 & 3.7 & $98.3 \pm 0.14$ & 1.74 & 2.3 \\
\hline -Silver coated & $99.3 \pm 0.30$ & 0.66 & 9.0 & $98.9 \pm 0.18$ & 1.02 & 4.0 \\
\hline Method (B) & $98.2 \pm 0.13$ & 1.83 & 4.8 & $98.4 \pm 0.16$ & 1.63 & 3.0 \\
\hline Method (C) & $99.3 \pm 0.27$ & 0.74 & 7.3 & $99.0 \pm 0.17$ & 0.97 & 3.4 \\
\hline \multicolumn{7}{|c|}{ Brom-PT electrode (II) } \\
\hline \multicolumn{7}{|l|}{ Method (A) } \\
\hline -Conventional & $99.4 \pm 0.08$ & 0.60 & 1.8 & $98.0 \pm 0.14$ & 2.00 & 2.3 \\
\hline -Graphite coated & $101.0 \pm 0.29$ & 1.00 & 8.4 & $99.5 \pm 0.21$ & 0.50 & 5.4 \\
\hline -Copper coated & $98.2 \pm 0.21$ & 0.90 & 5.6 & $98.2 \pm 0.14$ & 1.90 & 2.3 \\
\hline -Silver coated & $99.9 \pm 0.93$ & 0.40 & 4.8 & $99.7 \pm 0.12$ & 0.30 & 1.8 \\
\hline Method (B) & $98.2 \pm 0.21$ & 1.83 & 4.4 & $97.0 \pm 0.17$ & 2.45 & 3.4 \\
\hline Method (C) & $99.9 . \pm 0.39$ & 0.08 & 4.2 & $99.4 \pm 0.24$ & 0.60 & 6.7 \\
\hline
\end{tabular}

"RE: Relative error. $/^{* *}$ One - tailed critical F value./ Method (A): Standard additions method/ Method (B): FIA./Method (C): Conductimetric titration.

Tab. 1. Statistical treatment of data obtained for the determination of bromhexine hydrochloride using conventional and coated wire electrodes employing the standard additions method, FIA and by conductimetry in comparison with the official method.

\section{Conclusion}

The investigated electrodes were shown to be useful as potentiometric sensors for the determination of bromhexine hydrochloride and its pharmaceutical preparation, the proposed methods are characterized by high degree of precision and accuracy when compared with the official method (potentiometric titration), within wide concentration, temperature and $\mathrm{pH}$ ranges as shown by $\mathrm{F}$ - and $\mathrm{t}$-values. Comparing the results obtained from potentiometric determination of the drug in 
batch (using standard additions method) and FIA conditions and those obtained from the conductimetric titrations with the results obtained from the official method, it is clear that either Brom-TPB or Brom-PT electrode is recommended using FIA conditions since potentiometric and conductimetric titrations are time consuming (20 min in each run), in addition the application of the electrodes in FIA shortened the time required for the determination of the drug in its pure state or in its pharmaceutical preparation. Regarding coated wire electrodes, either Brom-TPB or Brom-PT graphite or silver coated wire electrodes is recommended for use because of its high life time compared to the copper coated electrode.

\section{References}

[1] Ribone M E, Pagani A P, Olivieri A C.

Determination of minor component bromhexine in cotrimoxazolecontaining tablets by absorption spectrophotometry and partial least squares (PLS-1) multivariate calibration.

J. Pharm. Biomed. Anal.2000; 23: 591-95.

[2] Dias A C B, Santos J L M, Lima J L F C, Zagatto E A G.

Muli-pumping flow system for spectrophotometric determination of bromhexine.

Anal. Chim. Acta, 2003; 499: 107-13.

[3] Bhatia N M, Jain D K, Triredi P.

Simultaneous analysis of sulbutamol and bromhexine hydrochloride from solid dosage form using multiwavelength UV-spectrophotometry. Indian Drugs, 1998; 35: 566-69

[4] Packert Jensen B, Gammelgaard B, Honore Hansen S, Vanggaarc Andersen J.

HPLC-ICP-MS compared with radiochemical detection for metabolit profiling of ${ }^{3} \mathrm{H}$-bromhexine in rat urine and faeces.

J. Anal. At. Spectrom., 2005; 20(3): 204-9.

[5] Kaskhedikar S G, Argal A.

Simulantaneous estimation of bromhexine hydrochloride and cephalexin in capsule by high performance liquid chromatography. Indian Drugs, 2001; 38: 137-39.

[6] Chu K- O, Tin K-C.

Analysis of antihistamines in cough syrup.

Anal. lett., 1998; 31: 1879-90. 
[7] Sanghavi N M, Samarth M M, Singh R, Matharu P S.

Colorimetric estimation of bromhexine hydrochloride and its formulations. Indian Drugs, 1990; 27: 486-88.

[8] Parimoo P, Kumar S.

Determination of bromhexine hyochloride by colorimetry, Indian Drugs, 1994; 31:41-43.

[9] Sumarlik E, Indrayanto G.

TLC-densitometric determination of bromhexine hydrochloride in pharmaceuticals and its validation.

J. Liq. Chromatogr. Relat. Technol.,2004; 27: 2047-56.

[10] Perez-Ruiz T, Martinez-Lozano C, Sanz A, Mondejar S.

Flow Injection extraction-spectrophotometric determination of bromhexine with orange IV.

J. Pharm. Biomed. Anal., 1995; 13: 1101-06.

[11] Yang L L, Yuan Y S, Tu X E.

Detrimination of bromhexine in plasma by gas chromatography-electron capture detection and pharmacokinetic studies.

General Hospital Nanjing Command PLA, Nanjing, Sepu, 2000; 18: 54345.

[12] Khalil S, Elrabiehi M M.

Bromhexine-selective PVC membrane electrode based on bromhexinium tetraphenylborate.

Microchem. J., 1999; 62: 237-43.

[13] Goicoechea H C, Olivieri A C.

Determination of bromhexine in cough-cold syrups by absorption spectrophotometry and multivariate calibration using partial least-squares and linear hybrid analyses. Application of a novel method of a wavelength selection.

Talanta, 1999; 49: 793-800.

[14] Pospisilova M, Polasek M, Jokl V.

Determination of ambroxol and bromhexine in pharmaceuticals by capillary isotachophoresis.

J. Pharm. Biomed. Anal., 2001; 24: 421-28.

[15] Rodriguez V G, Lucangioll S E, Otero G C F, Carducci C N.

Purity testing of drugs by capillary electrophoresis.

J. High Resolut. Chromatogr., 1996; 19:, 703-05.

[16] Perez-Ruiz T, Martinez-Lozano C, Sanz A, Bravo E.

Determination of bromhexine and amroxol in pharmaceutical dosage forms, urine and blood serum.

J. Chromatogr. Biomed. Applications, 1997; 692: 199-205. 
[17] Abdel-Ghani NT, Shoukry A F, El-Nashar R M.

Flow injection potentiometric determination of pipazethate hydrochloride. Analyst, 2001; 126: 79-85.

[18] Ibrahim H I, Issa Y M, Abu-Shawish H M.

Potentiometric flow injection analysis of drotaverine hydrochloride in pharmaceutical preparations.

Anal. Lett., 2005; 38: 111-17.

[19] Shoukry A F, Abdel-Ghani N T, Issa Y M, Ahmed H M.

Plastic membrane selective electrode for cetirizinium ion based on cetirizinium-tetraphenylborate.

Electroanalysis, 1999; 11: 443.

[20] Lingane J J

Electroanalytical Chemistry, $2^{\text {nd }}$ ed.,

Inter-sceince, New York, 1958, p. 90.

[21] Oesch U, Ammann D, Simon W.

Ion-selective membrane electrodes for clinical use.

Clin. Chem., 1986; 32: 1448-59.

[22] Trojanowicz M., Matuszewski W.

Limitation of Linear Response in Flow Injection Systems with Ion Selective Electrodes.

Anal. Chim. Acta, 1982; 138: 71-79.

[23] Ilcheva L, Trojanowicz M, Vel Krawczyk T K.

Effect of addition of main ion to carrier solution in potentiometric flow injection measurements with solid state ion-selective electrodes.

Fresenius' Z. Anal. Chem., 1987; 328: 27-32.

[24] Hulanicki A, Lewenstam A.

Model for Treatment of Selectivity Coefficients for Solid-State IonSelective Electrodes.

Anal. Chem., 1981;53:1401-5.

[25] Issa Y M, Abdel-Ghani N T, Shoukry A F, Ahmed H M.

New conventional coated wire ion-selective electrodes for flow injection potentiometric determination of chlordiazepoxide.

Anal. Sci., 2005; 21: 1037-42.

[26] Pungor E.

Ion-selective electrodes - Analogies and conclusions.

Electroanalysis, 1996; 8 No.4.

[27] Issa Y M Shoukry A F, El-Nashar R M.

Conductimetric Determination of Reproterol $\mathrm{HCl}$ and Pipazethate $\mathrm{HCl}$ and Sulbutamol sulphate in Their Pharmaceutical Formulations. Pharm. Biomed. Anal. J., 2001; 26: 379-86. 
[28] Baumann E.

Trace flouride determination with specific ion-selective electrode.

Anal.Chim. Acta, 1986; 42:127-132.

[29] Miller J C, Miller J N, Editors

Statistics for Analytical Chemistry,

New Yourk: John Wiley\& Sons 1984.

[30] European pharmacopoeia, $4^{\text {th }}$ Edn., 2002; 756-57. 